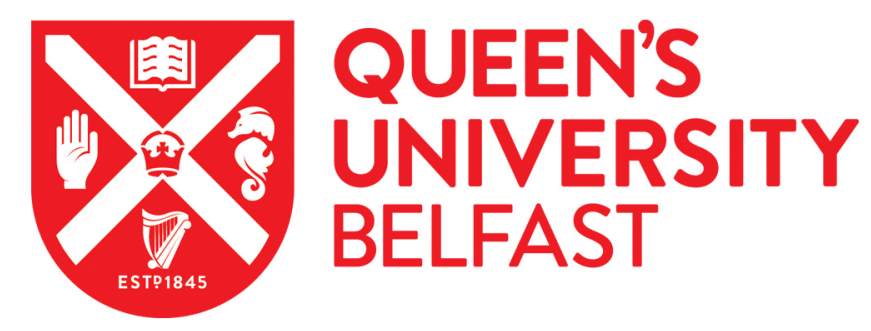

\title{
Understanding and Enhancing Sepsis Survivorship: Priorities for Research and Practice
}

International Sepsis Forum (2019). Understanding and Enhancing Sepsis Survivorship: Priorities for Research and Practice. American Journal of Respiratory and Critical Care Medicine. https://doi.org/10.1164/rccm.2018122383CP

Published in:

American Journal of Respiratory and Critical Care Medicine

Document Version:

Peer reviewed version

Queen's University Belfast - Research Portal:

Link to publication record in Queen's University Belfast Research Portal

Publisher rights

Copyright 2019 American Thoracic Society. This work is made available online in accordance with the publisher's policies. Please refer to any applicable terms of use of the publisher.

\section{General rights}

Copyright for the publications made accessible via the Queen's University Belfast Research Portal is retained by the author(s) and / or other copyright owners and it is a condition of accessing these publications that users recognise and abide by the legal requirements associated with these rights.

Take down policy

The Research Portal is Queen's institutional repository that provides access to Queen's research output. Every effort has been made to ensure that content in the Research Portal does not infringe any person's rights, or applicable UK laws. If you discover content in the Research Portal that you believe breaches copyright or violates any law, please contact openaccess@qub.ac.uk. 
Title: $\quad$ Understanding and Enhancing Sepsis Survivorship:

Priorities for Research and Practice

Authors: Prescott HC, Iwashyna TJ, Blackwood B, Calandra T, Chlan LL, Choong K, Connolly B, Dark P, Ferrucci L, Finfer S, Girard TD, Hodgson CL, Hopkins RO, Hough CL, Jackson JC, Jette AM, Machado FR, Marshall JC, Misak C, Needham DM, Panigrahi P, Reinhart K, Yende S, Zafonte $\mathrm{RD}$, Rowan KM, Angus DC.

\section{Correspondence:}

Hallie C. Prescott, MD, MSc

2800 Plymouth Road

North Campus Research Center

Bldg. 16, 341E

Ann Arbor, MI 48109-2800

Phone: 734-222-7423

Fax: 734-764-4556

Email: hprescot@med.umich.edu

Word Count: 3,080

Tables and Figures: 5

There is an online supplement.

\section{Funding and acknowledgements:}

Dr. Prescott was supported in part by K08 GM115859 from the National Institutes of Health. Dr. Choong was supported by AHSC AFP Innovation Fund no. 3576.3014214. Dr. Finfer was supported by Australian National Health and Medical Research Council (NHMRC) Practitioner Fellowship Grant 1117230. Dr. Hodgson was supported by a Heart Foundation Future Leader Fellowship from Australia. The views in this manuscript do not necessarily reflect the position or policy of the US government or Department of Veterans Affairs.

\section{List of Authors}

Hallie C. Prescott, MD, MSc

Department of Medicine, University of Michigan

VA Center for Clinical Management Research

Ann Arbor, MI, USA

Conflicts of interest-None 
Theodore J. Iwashyna, MD, PhD

Department of Medicine, University of Michigan

VA Center for Clinical Management Research

Ann Arbor, MI, USA

Conflicts of interest-None

Bronagh Blackwood, PhD, MSc, RGN, RNT

Wellcome-Wolfson Institute for Experimental Medicine,

Queen's University Belfast

Northern Ireland UK.

Conflicts of interest-None

Thierry Calandra, MD, PhD

Professor of Medicinem Infectious Diseases Service

Centre Hospitalier Universitaire Vaudois and University of Lausanne

Lausanne, Switzerland

Conflicts of Interest-None

Linda L. Chlan, PhD, RN, ATSF, FAAN

Department of Nursing, Nursing Research Division

Mayo Clinic College of Medicine and Science

Mayo Clinic

Conflicts of Interest-None

Karen Choong, MB, BCh, MSc

Department of Pediatrics and Critical Care

Department of Health Research Methods, Evidence and Impact, McMaster University

Hamilton, Ontario, Canada

Conflicts of Interest-None

Bronwen Connolly MSc, PhD, MCSP

Lane Fox Respiratory Unit

St Thomas' Hospital

Guy's \& St Thomas' NHS Foundation Trust

London, UK

Conflicts of Interest-None

Paul Dark, MD, PhD

NIHR National Specialty Lead for Critical Care,

Faculty of Life Sciences and Medicine,

King's College

London, UK

Conflicts of Interest-None

Luigi Ferrucci, MD, PhD

National Institute on Aging, US National Institutes of Health 
Baltimore, MD, USA

Conflicts of Interest-None

Simon Finfer, MD FCICM

The George Institute for Global Health, University of New South Wales

Sydney, Australia.

Conflicts of Interest-None

Timothy D Girard, MD, MSCl

Clinical Research, Investigation, and Systems Modeling of Acute illness (CRISMA)

Center,

Department of Critical Care Medicine, University of Pittsburgh School of Medicine

Pittsburgh, Pennsylvania, USA

Conflicts of Interest-None

Carol L. Hodgson, FACP, PhD

Australian and New Zealand Intensive Care Research Centre,

Monash University

Melbourne, Australia.

Conflicts of Interest-None

Ramona O. Hopkins, PhD

Psychology Department and Neuroscience Center

Brigham Young University, Provo, Utah

and

Center for Humanizing Critical Care at Intermountain Healthcare, Murray, Utah

and

Pulmonary and Critical Care Medicine, Intermountain Medical Center, Murray, Utah

Conflicts of Interest-None

Catherine L. Hough, MD MSc

Department of Medicine, Division of Pulmonary, Critical Care and Sleep Medicine University of Washington

Seattle, WA, USA

Conflicts of Interest-None

James C. Jackson, Psy.D.

Division of Allergy, Pulmonary, and Critical Care Medicine, Vanderbilt University

Nashville, Tennessee, USA

Conflicts of Interest-None

Alan M Jette, PhD, MPH, PT, FAPTA

Department of Physical Therapy, Massachusetts General Hospital Institute

Boston, Massachusetts, USA

Conflicts of Interest-None 
Flavia Machado, MD PhD

Anesthesiology, Pain, and Intensive Care Department

Federal University of São Paulo

São Paulo, Brazil

Conflicts of Interest-None

John C. Marshall MD

Departments of Surgery and Critical Care Medicine

Keenan Research Centre for Biomedical Science

St. Michael's Hospital

Toronto, Ontario, Canada

Cheryl Misak, DPhil

Professor of Philosophy

University of Toronto

Toronto, Ontario, Canada

Dale M. Needham, FCPA, MD, PhD

Pulmonary and Critical Care Medicine, and Physical Medicine and Rehabilitation, Johns Hopkins University

Baltimore, MD, USA

Pinaki Panigrahi, MD, PhD

Departments of Epidemiology and Pediatrics

University of Nebraska Medical Center

Omaha, NE, USA

Conflicts of Interest-None

Konrad Reinhart, MD

Department for Anesthesiology and Intensive Care Medicine, Jena University Hospital, and BIH Visiting Professor/Stiftung Charité Klinik für Anäesthesie operative

Intensivmedizin, Charité Universitätsmedizin

Berlin, Germany

Conflicts of Interest-None

Sachin Yende, MD MS

Veterans Affairs Pittsburgh Healthcare System

Department of Critical Care Medicine

University of Pittsburgh

Pittsburgh, PA, USA

Conflicts of Interest-None

Ross D. Zafonte, DO

Department of Physical Medicine and Rehabilitation, Spaulding Rehabilitation Hospital, Massachusetts General Hospital, Brigham and Women's Hospital Harvard Medical School 
Boston, Massachusetts, USA

Conflicts of Interest-None

Rowan, Kathryn, PhD

Intensive Care National Audit and Research Centre

London, UK

Conflicts of Interest-None

Derek C. Angus, MD, MPH

The Clinical Research, Investigation, and Systems Modeling of Acute Illness (CRISMA)

Center

Department of Critical Care Medicine, University of Pittsburgh School of Medicine

Pittsburgh, PA, USA

Conflicts of Interest-None 


\begin{abstract}
An estimated 14.1 million patients survive sepsis hospitalization each year. Many survivors experience poor long-term outcomes, including new or exacerbated neuropsychological impairment, functional disability, and heightened vulnerability to further health deterioration, including recurrent infection, cardiovascular events, and acute renal failure. However, current guidelines and interventional trials have focused on shorter-term survival, so there is little data on how to best promote longer-term recovery. To address this unmet need, a Colloquium on "Understanding and Enhancing Sepsis Survivorship" was held in February 2018, sponsored by the International Sepsis Forum. The goals of the Colloquium were to identify (1) gaps and limitations of current research, (2) shorter-term research priorities, and (3) longer-term research priorities for understanding and enhancing sepsis survivorship, informed by review of the literature and expert opinion. A total of 26 experts from 8 countries participated. The top three short-term priorities were to better leverage existing databases for research, to develop and disseminate educational resources on post-sepsis morbidity, and to build deep connections with sepsis survivors to define and achieve research priorities. The top longer-term priorities were to link mechanisms to long-term outcomes through large cohort studies with deep phenotyping, build a harmonized global sepsis registry from which patients could be enrolled into cohort studies or interventional trials, and to complete detailed longitudinal follow-up to characterize the heterogeneity of recovery experiences across sepsis survivors. This Perspective reports on the Colloquium discussions, the rationale for the research priorities, and current initiatives addressing these priorities.
\end{abstract}

Word Count: 242

Keywords: survivorship; critical illness; rehabilitation 


\section{INTRODUCTION}

Sepsis—life-threatening organ dysfunction caused by a dysregulated host response to infection-is a leading cause of global morbidity and mortality. An estimated 14.1 million adults and 2.5 million children survive sepsis each year ${ }^{1,2}$, and many survivors experience poor long-term outcomes ${ }^{3}$. Patients develop an average 1-2 new functional limitations following sepsis ${ }^{4}$, and $10-40 \%$ experience new cognitive impairment ${ }^{4-7}$. Anxiety $^{8}$, depression ${ }^{9}$, and post-traumatic stress disorder ${ }^{10}$ symptoms exceed population-level norms. Furthermore, sepsis survivors are vulnerable to further health problems $^{3}$. Up to $40 \%$ are re-hospitalized within 90 days ${ }^{11}$, and rates of recurrent infection, sepsis, cardiovascular events, acute renal failure, and aspiration are increased relative to age- and co-morbidity matched controls ${ }^{3,12-14}$. As a result, sepsis survivors are often unable to live independently after sepsis ${ }^{15}$, cannot return to work ${ }^{16}$, and have increased risk of dying for up to two years ${ }^{17}$. Thus, sepsis should be viewed as a life-changing and disability-inducing event.

A 2017 WHO resolution on sepsis called on member states to address the needs of survivors, recognizing the burden of longer-term sepsis-related morbidity ${ }^{18}$. However, guidelines have traditionally focused on early recognition and management, not mitigation of longer-term sequelae ${ }^{19}$. Likewise, clinical trials typically use shorter-term mortality endpoints and only rarely collect data on functional outcomes or quality of life $\mathrm{e}^{20,21}$. Perhaps not surprisingly given the lack of attention to sepsis survivorship, many patients report dissatisfaction with follow-up care after hospitalization ${ }^{22}$. 
To address this unmet need, a Colloquium on "Understanding and Enhancing Sepsis Survivorship" was held in February 2018, sponsored by the International Sepsis Forum. The Colloquium brought together a diverse group of healthcare professionals, researchers, and patient representatives to distill essential findings on sepsis survivorship and articulate how to improve longer-term recovery. This Perspective reports on gaps and limitations of current knowledge on sepsis survivorship; research priorities and their rationale; and current initiatives to address these priorities.

\section{METHODS}

The Colloquium chairs (HCP, KMR, DCA) identified participants based on their expertise and through snowball sampling by recommendation. Participants outside critical care and infectious disease were intentionally invited to provide experience and examples of successes in analogous areas. Collectively, the group had expertise in sepsis, critical care, infectious diseases, geriatrics; physical medicine \& rehabilitation, psychology, and physiotherapy.

During the Colloquium, we used "nominal group technique" to rapidly gain consensus on research priorities. This process involves problem identification, solution generation, and decision making by group vote ${ }^{23}$. Prior to Colloquium, participant were asked to consider gaps and limitations of current research (based on literature review and their expert opinion), then generate potential next steps to move the field forward. During the Colloquium, ideas were shared through presentations and group discussion (see Online Supplement, Appendix 1 for Colloquium agenda). At the end of the Colloquium, 
participants listed potential next steps over a two-year and ten-year horizon-to "do more with what we have" in the shorter-term and "develop and deliver more" in the longer-term. Ideas were prioritized by group vote. Each participant could cast 12 votes, 6 for shorter-term and 6 for longer-term priorities. Votes could be allocated in any wayall 6 for a single idea or split amongst several ideas. Following the Colloquium, the organizing chairs drafted the manuscript, which was circulated to participants for critical appraisal, revision, and final approval.

\section{RESULTS}

\section{Summary of Evidence}

Our discussion was informed by recent comprehensive reviews on adult sepsis survivorship $^{3}$ and pediatric critical illness survivorship ${ }^{24}$. In addition, participants identified 30 recent systematic reviews pertinent to sepsis survivorship (Table 1). The main findings, as well as the gaps and limitations identified by these systematic reviews, are summarized in Supplemental Table 1.

\section{Limitations of Existing Research}

Participants identified the following limitations of as most important: (1) variable inclusion/exclusion criteria, outcomes measures, and timing of outcome assessments, making it difficult to pool studies to yield larger and more generalizable study populations, and (2) small or non-representative patient populations (Supplemental Tables 1, 2, Supplemental Figure 1). 


\section{Gaps in Research}

Participants identified the following gaps as most important: (1) limited data on longerterm outcomes of specific patient populations, such as pediatric sepsis survivors and the majority of sepsis survivors who reside in low or middle-income countries; (2) limited data on outcomes beyond one year; (3) few studies of in-hospital or post-hospital interventions to enhance longer-term survival and quality of life; (4) limited data on how to identify patients most likely to benefit from interventions (Supplemental Tables 1, 3, Supplemental Figure 1). In particular, more research is needed to define the benefit and optimal delivery of early mobilization; physical rehabilitation; early cognitive rehabilitation; peer-support; supportive interventions for caregivers; and interventions to assist survivors in adapting to new limitations.

\section{Successes in Related Fields}

Relevant expert participants presented models of success in the fields of cancer, dementia, stroke, and traumatic brain injury that each have research programs promoting recovery and/or adaptation to new limitations (Table 2). Dedicated follow-up clinics, which serve both to support patients and to generate and test research hypotheses, exist for each of these conditions in at least some countries. Additionally, these fields, particularly cancer, have large-scale public awareness campaigns, philanthropy-funded research programs, successful integration of patients into the prioritization of research questions, and large-scale longitudinal registries. These solutions should be adapted and applied to sepsis survivorship. 


\section{Is Sepsis Survivorship Unique?}

During the Colloquium, we considered the extent to which sepsis survivorship is a unique problem. Many challenges are shared with broader populations of patients surviving an acute illness 25,26 _as described by "post-hospital syndrome"27 (an acquired, transient period of generalized risk for a range of adverse health events); "post-intensive care syndrome"28 (new or worsened physical, cognitive, or emotional morbidity after critical illness); and "persistent inflammation, immunosuppression, and catabolism syndrome"29 (a collection persistent physiologic derangements following sepsis, trauma, or major surgery). Moreover, patients' experiences after sepsis are often influenced by multi-morbidity, frailty, and progressively declining health prior to sepsis ${ }^{30,31}$. For this reason, the magnitude and type of post-sepsis problems measured in studies depends heavily on the comparison-whether sepsis survivors are compared to age- and gender-matched population controls, patients hospitalized for infection, or to other ICU patients.

Despite the overlap with other populations, there are some benefits to focusing research and treatment on sepsis survivors rather than general ICU survivors. Serious sequelae of sepsis are not limited to patients treated in an ICU. Furthermore, organizing educational information around sepsis may be more accessible to patients, who rarely self-identify as ICU survivors. Indeed, a growing number of websites provide information on "life after sepsis"32,33, "post-sepsis symptoms"34, or "post-sepsis syndrome"35,36. 


\section{Discussion Themes}

The following themes emerged as central foci (Figure 2):

- Promoting education, advocacy, and patient engagement. Awareness of sepsis sequelae is poor among general public and clinicians outside critical care. Advancing research and treatment of sepsis survivors requires broader awareness-to direct patients to existing resources, define and refine best practices for clinical management, and increase research funding. Finally, there is limited interaction between researchers and patient engagement groups, missing a critically important opportunity.

- Building clinical infrastructure. Sepsis survivors are treated by a variety of healthcare providers across diverse clinical settings. Specialized follow-up, such as critical illness follow-up clinics or sepsis centers of excellence, is one possible approach to address the multi-faceted problems faced by sepsis survivors and mitigate secondary disabilities. By concentrating learning-by-doing and providing a setting to pilot and test novel rehabilitation strategies more efficiently, centralized follow-up programs may advance care. For example, the Society of Critical Care Medicine's International Thrive Collaboratives for ICU Peer Support ${ }^{37}$ and ICU Follow-up Clinics ${ }^{38}$ provide a setting to learn through shared experiences. However, because many sepsis survivors cannot travel to centralized clinics, care models must be expanded beyond traditional in-person clinics, potentially incorporating remote monitoring, telehealth, and in-home visits. 
Alternatively, lessons learned from specialized follow-up clinics must be scaled for broader delivery.

- Improving research methodology. Better research tools are needed to identify the mechanisms underlying post-sepsis morbidity and identify successful interventions. Particular areas of need include robust and proximal surrogate outcome measures that distinguish underlying mechanism of injury; measures that precisely characterize patient outcomes while minimizing response burden; theory-guided interventions (i.e., tailoring interventions to the mechanism/type of impairment), longer duration of longitudinal follow-up, and translational studies leveraging multi-modal assessment (from gene expression through patient reported outcomes).

\section{Prioritization of Short- and Long-Term Research Goals}

The top short-term priorities were: (1) merging ICU databases across countries and developing consensus harmonized data elements for such databases ( $15.2 \%$ of votes); (1) developing and disseminating educational materials for patients, families, and clinicians (15.2\%); and (3) making deep connections with survivor groups to define and achieve research priorities (14.5\%) (Figure 2). Full voting on short-term priorities is presented in Supplemental Table 5.

Top long-term priorities were (1) building an integrated global cohort study linking mechanism to long-term outcomes (17.4\% of votes); (2) building a global sepsis cohort 
to feed into observational and interventional trials (15.9\%), and (3) incorporating detailed long-term longitudinal follow up to characterize trajectories of recovery/survivorship across patients (14.5\%) (Figure 2). Full voting on long-term priorities is presented in Supplemental Tables 6.

\section{Shorter-Term Priority 1: Harmonizing and linking existing ICU databases}

A number of high-quality ICU databases ${ }^{39-41}$, while not primarily developed for research, have proved valuable to answering research questions. Moreover, ICU databases have recently been developed in several lower and middle-income counties ${ }^{42-44}$. However, these databases are rarely linked to each other or to other data sources. As such, research questions are often limited to those that can be answered within the single database, constraining generalizability to select regions or hospital systems, and to the shorter-term outcomes collected.

Investing in data linkages would realize the full potential of existing data, facilitate longer-term follow-up, and enable cross-system comparisons. For example, Brazil's Organizational CHaractEriSTics in cRitical cAre study (ORCHESTRA) database was recently linked to the UK's Intensive Care National Audits \& Research Centre (ICNARC) Case Mix Programme database to compare prevalence and outcomes of ICU-treated sepsis between Brazil and England ${ }^{45}$. 
Importantly, it is not necessary to share patient-level data. Rather, analyses can be completed in secure data enclaves ${ }^{46}$ or by pooling aggregate results, as was done for the Sepsis-3 validation ${ }^{47}$ and evaluation of US sepsis incidence ${ }^{48}$.

Beyond linking existing databases, ICU dataset specifications should be harmonized, such that basic demographic, illness severity, and treatment data are collected in a consistent manner on consistent scales to facilitate comparison.

\section{Shorter-Term Priority 2: Developing and disseminating educational materials.}

Public awareness of sepsis has increased in recent years, but recognition still lags behind other acute medical conditions ${ }^{49}$, and awareness of long-term sequelae (e.g. physical and neuropsychological impairment, increased risk for recurrent infection) remains particularly low. The challenges of sepsis survivorship are not covered in current sepsis guidelines ${ }^{19}$ and are rarely discussed during hospitalization ${ }^{22,50}$.

Several educational resources on sepsis survivorship have been developed $32,33,36,51,52$. However, these materials must be disseminated more broadly. Panelists recommend: (1) educating patients and families about life after sepsis in the peri-discharge period; (2) developing and disseminating educational materials to clinicians working in postacute care facilities and the outpatient setting, such as this recent perspective on sepsis survivorship geared towards physical therapists ${ }^{53}$; and (3) incorporating education on sepsis sequelae into medical school curriculum, professional society conferences, and continuing medical education opportunities. 


\section{Shorter-Term Priority 3: Building deep connections with survivor groups to define}

and achieve research priorities.

Patient advocacy groups play an important role in defining research priorities and funding research for many diseases. For example, the Cystic Fibrosis Foundation funds drug development and randomized clinical trials. Their website reports that "nearly every CF drug was made possible by the Foundation and because of funds raised from Great Strides [walks]"54.

Sepsis advocacy groups—such as Global Sepsis Alliance ${ }^{55}$, UK Sepsis Trust ${ }^{56}$, Latin American Sepsis Institute ${ }^{57}$, Sepsis Alliance ${ }^{58}$, and Rory Staunton Foundation ${ }^{59}$-have spurred large-scale awareness and quality improvement initiatives, such as World Sepsis Day ${ }^{60,61}$, nationwide quality improvement programs in Brazil" ${ }^{62}$, and "Rory's Regulations" in New York ${ }^{63,64}$. These efforts have saved lives. Moreover, in 2017, the World Health Organization passed a resolution recognizing sepsis as a global health priority ${ }^{18}$

Despite these successes, patients have historically been absent from defining sepsis research priorities. Going forward, researchers must better engage with sepsis survivors to advance sepsis research. Recent examples of increased public involvement include: (1) collaboration of patients, caregivers, and clinicians to create the James Lind Alliance's top 10 research questions for intensive care ${ }^{65}$; (2) inclusions of multiple public members on the current Surviving Sepsis Campaign Guidelines panel; (3) inclusion of 
patient and caregiver representatives on the Delphi panel for developing core outcomes measures for acute respiratory distress syndrome survivors ${ }^{66,67}$; and (4) co-design of critical illness follow-up clinics by patients and clinicians ${ }^{68,69}$.

\section{Longer-Term Priorities:}

(1) A global cohort study linking mechanism to long-term outcomes;

(2) A global sepsis registry, from which patients could be enrolled into observational and interventional studies;

(3) Detailed long-term longitudinal follow up to characterize the heterogeneity of recovery across sepsis survivors.

We believe the long-term priorities are best tackled jointly through a systematic research program on sepsis survivorship (Figure 3). The European Prevention of Alzheimer's Dementia (EPAD) Consortium—a multi-national industry-academia initiative to "create a novel environment for testing numerous interventions targeted at the prevention of Alzheimer's dementia"-could serve as a model ${ }^{70}$. EPAD aims to advance anti-dementia research and treatment by: (1) improving patients' access to existing cohorts and registers; (2) developing a master registry of patients at increased risk of Alzheimer's; (3) establishing a longitudinal cohort study of 6,000 patients; and (4) deploying a proof-of-concept adaptive trial, enrolling patients from the master registry of at-risk patients ${ }^{71}$. In essence, EPAD connects existing registries and serves as a unified entry point into early-phase clinical trials. 
Similar infrastructure could dramatically accelerate sepsis research. Akin to EPAD, a sepsis consortium could start as a harmonized international registry, bringing together existing sepsis registries, such as the Mid-German Sepsis Cohort ${ }^{72}$. From the harmonized registry, patients could be screened and invited to join longitudinal cohort studies. Participation in the consortium could provide a venue for education and peersupport, potentially providing immediate benefits to participants and encouraging retention. Over the longer-term, it would improve understanding of post-sepsis sequelae. Ultimately, adaptive platform trials could be incorporated to test putative interventions after sepsis.

The major limitation to a free-standing sepsis consortium, however, is that data on presepsis health status could be collected only retrospectively. To overcome this limitation, the consortium could be embedded within large ongoing cohort studies (e.g. UK Biobank $^{73}$, Norway's HUNT Study ${ }^{74}$, US National Institutes of Health's All of Us Research Program ${ }^{75}$, US Department of Veterans Affairs' Million Veterans Program ${ }^{76}$ ), which already collect genetic and health data on millions of individuals.

Cohort studies (e.g. US Health and Retirement Study ${ }^{77}$, Cardiovascular Health Study ${ }^{78}$ ), have already been leveraged to measure the impact of pre-sepsis health status/trajectory on sepsis outcomes ${ }^{30,79}$. However, in these studies, sepsis cases were identified by diagnosis codes in linked claims data, and there is limited data on patient outcomes in the months after sepsis hospitalization. 
Prospectively embedding a sepsis consortium within ongoing cohort studies would provide several distinct benefits over existing research, including: (1) accurate identification of sepsis cases by prospectively collecting data on all potential sepsis hospitalizations, (2) better characterization of sepsis, and (3) increased intensively of data collection to characterize recovery after sepsis (e.g. serial collection of biospecimens and patient-reported outcomes).

A global, harmonized sepsis consortium would be a natural arena to advance standardized core baseline variables and core outcome sets for sepsis ${ }^{80}$; refine their measurement across the continuum of sepsis; and develop platforms to collect such information across participating sites, drawing directly from electronic health records and existing databases when possible. The consortium could also promote nonmortality outcomes, following the US Federal Drug Administration's "Critical Path" process for proxy outcome development ${ }^{81}$, and select from existing (or develop new) IRT-based instruments to measure core outcomes in a way that maximizes information and minimizes participant burden.

Sepsis survivorship research has often focused on a particular outcome (e.g. cognitive function, physical function, healthcare utilization) or a particular aspect of the underlying mechanistic pathways driving morbidity and mortality (e.g. genomics, transcriptomics, or proteomics in isolation). However, a sepsis consortium could support broad translational studies—simultaneously examining genomic and transcriptomic host response along 
with multi-faceted patient outcomes_to understand the mechanisms driving the longterm morbidity and mortality (Figure 2).

Finally, while prior cohort studies have defined the average experience of patients in the year after sepsis, there is wide heterogeneity of experiences across individual patients. It is hypothesized that there are characteristic trajectories of recovery, adaptation, and ongoing/progressive disability after sepsis ${ }^{82}$. A sepsis consortium could support large, population-based cohorts with detailed longitudinal follow-up necessary to: (1) objectively identify and define the characteristic pathways of recovery versus disability after sepsis; (2) predict a patient's likely post-sepsis trajectory; (3) identify modifiable factors influencing a patient's recovery experience that could be targeted in future interventional studies (Figure 3).

\section{Additional areas of focus}

Beyond the top research priorities, there was considerable interest in: (1) developing an item-response theory (IRT) computerized adaptive testing (CAT) question bank for longterm sepsis outcomes, and (2) developing better animal models of sepsis.

Current instruments to assess post-sepsis outcomes (e.g. neuropsychological status, quality of life) may not detect subtle declines—but detailed assessments impose expense and respondent burden. CAT characterizes a person's ability more precisely and efficiently than standard surveys, is used widely in other settings (e.g. intelligence testing), and was recently used to study functional recovery after pediatric critical 
illness ${ }^{83}$. CAT would be useful for characterizing heterogeneous outcomes of sepsis survivors, but questions must first be selected and calibrated for use.

For pre-clinical studies, animal sepsis models reproduce many of the acute immune defects seen in septic patients, but are currently insufficient for studying longer term recovery. In most instances, animals are young, have no co-morbid disease, and are not treated with typical sepsis therapies (e.g. antibiotics, fluids, supplemental oxygen). Furthermore, as the goal is often to study short-term survival, animal models have been designed such that only a minority of animals survive the insult. These limitations have been addressed in a recent expert consensus initiative for improving animal modeling in sepsis, which aims to improve the translation of preclinical findings ${ }^{84}$.

\section{CONCLUSION}

Sepsis is a common cause of hospitalization that frequently results in new morbidity. Shorter-term priorities to improve outcomes for survivors include leveraging existing databases, improving awareness of post-sepsis morbidity, and connecting with sepsis survivors to define and achieve research priorities. Longer-term priorities are to understand the mechanisms driving long-term sequalae and characterize heterogeneity of recovery experiences, both of which will inform future interventions. These longerterm priorities may be best accomplished through a global, harmonized sepsis research consortium embedded within existing large prospective cohorts. 


\section{REFERENCES}

1. Fleischmann C, Scherag A, Adhikari NKJ, et al. Assessment of Global Incidence and Mortality of Hospital-treated Sepsis. Current Estimates and Limitations. American Journal of Respiratory and Critical Care Medicine 2016;193:259-72.

2. Fleischmann-Struzek C, Goldfarb DM, Schlattmann P, Schlapbach LJ, Reinhart $\mathrm{K}$, Kissoon N. The global burden of paediatric and neonatal sepsis: a systematic review. Lancet Respir Med 2018;6:223-30.

3. Prescott HC, Angus DC. Enhancing Recovery From Sepsis. JAMA 2018;319:6275.

4. Iwashyna TJ, Ely EW, Smith DM, Langa KM. Long-term cognitive impairment and functional disability among survivors of severe sepsis. JAMA 2010;304:1787-94. 5. Needham DM, Colantuoni E, Dinglas VD, et al. Rosuvastatin versus placebo for delirium in intensive care and subsequent cognitive impairment in patients with sepsisassociated acute respiratory distress syndrome: an ancillary study to a randomised controlled trial. The Lancet Respiratory Medicine 2016;4:203-12.

6. Pandharipande PP, Girard TD, Jackson JC, et al. Long-term cognitive impairment after critical illness. N Engl J Med 2013;369:1306-16.

7. Girard TD, Thompson JL, Pandharipande PP, et al. Clinical phenotypes of delirium during critical illness and severity of subsequent long-term cognitive impairment: a prospective cohort study. The Lancet Respiratory Medicine 2018;6:21322.

8. Nikayin S, Rabiee A, Hashem MD, et al. Anxiety symptoms in survivors of critical illness: a systematic review and meta-analysis. General Hospital Psychiatry 2016;43:239.

9. Rabiee A, Nikayin S, Hashem MD, et al. Depressive symptoms after critical illness: A systematic review and meta-analysis. Critical Care Medicine 2016;44:174453.

10. Parker AM, Sricharoenchai T, Raparla S, Schneck KW, Bienvenu OJ, Needham DM. Posttraumatic stress disorder in critical illness survivors: a metaanalysis. Crit Care Med 2015;43:1121-9.

11. Prescott HC, Langa KM, Iwashyna TJ. Readmission diagnoses after hospitalization for severe sepsis and other acute medical conditions. JAMA 2015;313:1055-7.

12. Yende S, Linde-Zwirble W, Mayr F, Weissfeld LA, Reis S, Angus DC. Risk of cardiovascular events in survivors of severe sepsis. American Journal of Respiratory and Critical Care Medicine 2014;189:1065-74.

13. Shen H-N, Lu C-L, Yang H-H. Risk of Recurrence After Surviving Severe Sepsis. Critical Care Medicine 2016;44:1833-41.

14. Ou S-M, Chu H, Chao P-W, et al. Long-Term Mortality and Major Adverse Cardiovascular Events in Sepsis Survivors. A Nationwide Population-based Study. American Journal of Respiratory and Critical Care Medicine 2016;194:209-17.

15. Yende S, Austin S, Rhodes A, et al. Long-Term Quality of Life Among Survivors of Severe Sepsis. Critical Care Medicine 2016;44:1461-7.

16. Poulsen JB, Moller K, Kehlet H, Perner A. Long-term physical outcome in patients with septic shock. Acta Anaesthesiologica Scandinavica 2009;53:724-30. 
17. Prescott HC, Osterholzer JJ, Langa KM, Angus DC, Iwashyna TJ. Late mortality after sepsis: Propensity matched cohort study. BMJ (Online) 2016;353.

18. Reinhart K, Daniels R, Kissoon N, Machado FR, Schachter RD, Finfer S.

Recognizing Sepsis as a Global Health Priority - A WHO Resolution. The New England Journal of Medicine 2017.

19. Rhodes A, Evans LE, Alhazzani W, et al. Surviving Sepsis Campaign:

International Guidelines for Management of Sepsis and Septic Shock: 2016. Intensive Care Medicine 2017;45:486-552.

20. Harhay MO, Wagner J, Ratcliffe SJ, et al. Outcomes and statistical power in adult critical care randomized trials. American Journal of Respiratory and Critical Care Medicine 2014;189:1469-78.

21. Gaudry S, Messika J, Ricard JD, et al. Patient-important outcomes in randomized controlled trials in critically ill patients: a systematic review. Ann Intensive Care 2017;7:28.

22. Huang CY, Daniels R, Lembo A, et al. Life after sepsis: an international survey of survivors to understand the post-sepsis syndrome. Int J Qual Health Care 2018.

23. Delbecq AL, Van de Ven AH. A Group Process Model for Problem Identification and Program Planning. The Journal of Applied Behavioral Science 1971;7:466-92.

24. Watson RS, Choong K, Colville G, et al. Life after Critical Illness in ChildrenToward an Understanding of Pediatric Post-intensive Care Syndrome. J Pediatr 2018;198:16-24.

25. Thompson K, Taylor C, Jan S, et al. Health-related outcomes of critically ill patients with and without sepsis. Intensive Care Medicine 2018;44:1249-57.

26. Hodgson CL, Walsh TS, Lone N. The long road home: are outcomes different for patients with sepsis? Intensive Care Medicine 2018;44:1556-7.

27. Krumholz HM. Post-hospital syndrome--an acquired, transient condition of generalized risk. N Engl J Med 2013;368:100-2.

28. Needham DM, Davidson J, Cohen $\mathrm{H}$, et al. Improving long-term outcomes after discharge from intensive care unit: report from a stakeholders' conference. Crit Care Med 2012;40:502-9.

29. Gentile LF, Cuenca AG, Efron PA, et al. Persistent inflammation and immunosuppression: a common syndrome and new horizon for surgical intensive care. J Trauma Acute Care Surg 2012;72:1491-501.

30. Prescott HC, Carmichael AG, Langa KM, Gonzalez R, Iwashyna TJ. Paths into Sepsis: Trajectories of Presepsis Healthcare Use. Ann Am Thorac Soc 2019;16:116-23. 31. Ferrante LE, Pisani MA, Murphy TE, Gahbauer EA, Leo-Summers LS, Gill TM. The Association of Frailty With Post-ICU Disability, Nursing Home Admission, and Mortality: A Longitudinal Study. Chest 2018;153:1378-86.

32. Life After Sepsis. 2019. (Accessed 04/08/2019, 2019, at

https://www.australiansepsisnetwork.net.au/community-awareness/life-sepsis.)

33. Life after sepsis fact sheet; what sepsis survivors need to know. (Accessed 04/08/2019, at https://www.cdc.gov/sepsis/pdfs/life-after-sepsis-fact-sheet.pdf.)

34. Post-Sepsis Symptoms (PSS). (Accessed 04/08/2019, at https://www.globalsepsis-alliance.org/sepsis.)

35. Post Sepsis Syndrome. (Accessed 04/08/2019, at https://sepsistrust.org/getsupport/support-for-survivors/post-sepsis-syndrome/.) 
36. Post-Sepsis Syndrome. (Accessed 11/04/2018, at

http://www.sepsisalliance.org/sepsis/post sepsis syndrome/.)

37. McPeake J, Hirshberg EL, Christie LM, et al. Models of Peer Support to

Remediate Post-Intensive Care Syndrome: A Report Developed by the Society of

Critical Care Medicine Thrive International Peer Support Collaborative. Crit Care Med 2019;47:e21-e7.

38. THRIVE Post ICU Clinic Collaborative. (Accessed 04/08/2019, at

https://www.sccm.org/Research/Quality/THRIVE/THRIVE-Post-ICU-Clinic-

Collaborative.)

39. Harrison DA, Brady AR, Rowan K. Case mix, outcome and length of stay for admissions to adult, general critical care units in England, Wales and Northern Ireland: the Intensive Care National Audit \& Research Centre Case Mix Programme Database. Critical Care (London, England) 2004;8:R99-111.

40. van de Klundert N, Holman R, Dongelmans DA, de Keizer NF. Data Resource Profile: the Dutch National Intensive Care Evaluation (NICE) Registry of Admissions to Adult Intensive Care Units. International Journal of Epidemiology 2015;44:1850-h.

41. Adult Patient Database (APD) - ANZICS. (Accessed 12/21/2018, at https://www.anzics.com.au/adult-patient-database-apd/.)

42. Hashmi M, Beane A, Taqi A, et al. Pakistan Registry of Intensive CarE (PRICE): Expanding a lower middle-income, clinician-designed critical care registry in South Asia. Journal of the Intensive Care Society 2018;0:1-6.

43. Zampieri FG, Soares M, Borges LP, Salluh JIF, Ranzani OT. The Epimed Monitor ICU Database $®$ : a cloud-based national registry for adult intensive care unit patients in Brazil. Revista Brasileira De Terapia Intensiva 2017;29:418-26.

44. National Intensive Care Surveillance; A critical care clinical registry and bed availability system for Sri Lanka. (Accessed 04/08/2019, at https://nicslk.wordpress.com.)

45. Ranzani OT, Shankar-Hari M, Harrison DA, et al. A Comparison of Mortality From Sepsis in Brazil and England: The Impact of Heterogeneity in General and SepsisSpecific Patient Characteristics. Crit Care Med 2019;47:76-84.

46. Platt R, Lieu T. Data Enclaves for Sharing Information Derived From Clinical and Administrative Data. JAMA 2018;320:753-4.

47. Seymour CW, Liu VX, Iwashyna TJ, et al. Assessment of Clinical Criteria for Sepsis: For the Third International Consensus Definitions for Sepsis and Septic Shock (Sepsis-3). JAMA 2016;315:762-74.

48. Rhee C, Dantes R, Epstein L, et al. Incidence and Trends of Sepsis in US Hospitals Using Clinical vs Claims Data, 2009-2014. JAMA 2017;318:1241-9.

49. Kerrigan SW, Martin-Loeches I. Public awareness of sepsis is still poor: we need to do more. Intensive Care Medicine 2018;44:1771-3.

50. Govindan S, Iwashyna TJ, Watson SR, Hyzy RC, Miller MA. Issues of survivorship are rarely addressed during intensive care unit stays. Baseline results from a statewide quality improvement collaborative. Ann Am Thorac Soc 2014;11:587-91.

51. Patient Education Video: Recovery After a Sepsis Hospitalization. (Accessed 04/08/2019, at https://www.youtube.com/watch?v=LmTMrdrKMjU.)

52. Prescott HC, Angus DC. Postsepsis Morbidity. JAMA 2018;319:91.

53. Jette AM. Enhancing Recovery After Sepsis. Phys Ther 2018;98:459-60. 
54. Why We Stride - Great Strides - Cystic Fibrosis Foundation. (Accessed

08/03/2018, at http://fightcf.cff.org/site/PageServer?pagename=gs why we stride.)

55. Global Sepsis Alliance. (Accessed 11/04/2018, at https://www.global-sepsisalliance.org/.)

56. UK Sepsis Trust. (Accessed 11/04/2018, at https://sepsistrust.org/.)

57. ILAS - Instituto Latino Americano da Sepse. 2018. (Accessed 11/04/2018, at http://www.ilas.org.br/.)

58. Sepsis Alliance. (Accessed 11/04/2018, at https://www.sepsis.org/.)

59. Rory Staunton Foundation - Sepsis education, awareness and prevention.

(Accessed 11/04/2018, at https://rorystauntonfoundationforsepsis.org/.)

60. Reinhart K, Daniels R, Kissoon N, et al. The burden of sepsis-a call to action in support of World Sepsis Day 2013. Journal of Critical Care 2013;28:526-8.

61. Savelkoel J, Claushuis TAM, van Engelen TSR, Scheres LJJ, Wiersinga WJ. Global impact of World Sepsis Day on digital awareness of sepsis: an evaluation using Google Trends. Critical Care (London, England) 2018;22:61.

62. Noritomi DT, Ranzani OT, Monteiro MB, et al. Implementation of a multifaceted sepsis education program in an emerging country setting: clinical outcomes and costeffectiveness in a long-term follow-up study. Intensive Care Medicine 2014;40:182-91. 63. Staunton O, Staunton C. The Urgency of Now: Attacking the Sepsis Crisis. Critical Care Medicine 2018;46:809-10.

64. Levy MM, Gesten FC, Phillips GS, et al. Mortality Changes Associated with Mandated Public Reporting for Sepsis. The Results of the New York State Initiative. Am J Respir Crit Care Med 2018;198:1406-12.

65. Intensive Care Top 10. (Accessed 04/08/2019, at

http://www.jla.nihr.ac.uk/priority-setting-partnerships/intensive-care/top-10-priorities/.)

66. Turnbull AE, Sepulveda KA, Dinglas VD, Chessare CM, Bingham CO, 3rd, Needham DM. Core Domains for Clinical Research in Acute Respiratory Failure Survivors: An International Modified Delphi Consensus Study. Crit Care Med 2017;45:1001-10.

67. Needham DM, Sepulveda KA, Dinglas VD, et al. Core Outcome Measures for Clinical Research in Acute Respiratory Failure Survivors. An International Modified Delphi Consensus Study. Am J Respir Crit Care Med 2017;196:1122-30.

68. McPeake J, Iwashyna TJ, Devine H, MacTavish P, Quasim T. Peer support to improve recovery following critical care discharge: a case-based discussion. Thorax 2017;72:856-8.

69. Haines KJ, Holdsworth C, Cranwell K, et al. Development of a Peer Support Model Using Experience-Based Co-Design to Improve Critical Care Recovery. Critical Care Explorations 2019;1:e0006.

70. Welcome to EPAD. (Accessed 06/21/2018, at http://epad.org/.)

71. Ritchie CW, Molinuevo JL, Truyen L, et al. Development of interventions for the secondary prevention of Alzheimer's dementia: the European Prevention of Alzheimer's Dementia (EPAD) project. The Lancet Psychiatry 2016;3:179-86.

72. Scherag A, Hartog CS, Fleischmann C, et al. A patient cohort on long-term sequelae of sepsis survivors: study protocol of the Mid-German Sepsis Cohort. BMJ Open 2018;7:e016827. 
73. Bycroft C, Freeman C, Petkova D, et al. The UK Biobank resource with deep phenotyping and genomic data. Nature 2018;562:203-9.

74. Krokstad S, Langhammer A, Hveem K, et al. Cohort Profile: the HUNT Study, Norway. Int J Epidemiol 2013;42:968-77.

75. National Institutes of Health. All of US. (Accessed 04/23/2019, at https://allofus.nih.gov.)

76. Gaziano JM, Concato J, Brophy M, et al. Million Veteran Program: A megabiobank to study genetic influences on health and disease. J Clin Epidemiol 2016;70:214-23.

77. Sonnega A, Faul JD, Ofstedal MB, Langa KM, Phillips JWR, Weir DR. Cohort Profile: the Health and Retirement Study (HRS). International Journal of Epidemiology 2014;43:576-85.

78. Fried LP, Borhani NO, Enright $P$, et al. The Cardiovascular Health Study: design and rationale. Ann Epidemiol 1991;1:263-76.

79. Shah FA, Pike F, Alvarez K, et al. Bidirectional relationship between cognitive function and pneumonia. American Journal of Respiratory and Critical Care Medicine 2013;188:586-92.

80. Blackwood B, Marshall J, Rose L. Progress on core outcome sets for critical care research. Current Opinion in Critical Care 2015;21:439-44.

81. Critical Path Initiative. (Accessed 04/08/2019, at https://www.fda.gov/scienceresearch/specialtopics/criticalpathinitiative/default.htm.)

82. Iwashyna TJ. Trajectories of Recovery and Dysfunction after Acute IIIness, with Implications for Clinical Trial Design. American Journal of Respiratory and Critical Care Medicine 2012;186:302-4.

83. Choong K, Fraser D, Al-Harbi S, et al. Functional Recovery in Critically III Children, the "WeeCover" Multicenter Study. Pediatric Critical Care Medicine: A Journal of the Society of Critical Care Medicine and the World Federation of Pediatric Intensive and Critical Care Societies 2018;19:145-54.

84. Osuchowski MF, Ayala A, Bahrami S, et al. Minimum Quality Threshold in PreClinical Sepsis Studies (MQTiPSS): An International Expert Consensus Initiative for Improvement of Animal Modeling in Sepsis. Shock 2018;50:377-80.

85. Calsavara AJC, Nobre V, Barichello T, Teixeira AL. Post-sepsis cognitive impairment and associated risk factors: A systematic review. Aust Crit Care 2018;31:242-53.

86. Sakusic A, O'Horo JC, Dziadzko M, et al. Potentially Modifiable Risk Factors for Long-Term Cognitive Impairment After Critical IIIness: A Systematic Review. Mayo Clin Proc 2018;93:68-82.

87. Barichello T, Sayana P, Giridharan VV, et al. Long-Term Cognitive Outcomes After Sepsis: a Translational Systematic Review. Mol Neurobiol 2019;56:186-251.

88. Johnson CC, Suchyta MR, Darowski ES, et al. Psychological Sequelae in Family Caregivers of Critically-III Intensive Care Unit Patients: A Systematic Review. Ann Am Thorac Soc 2019.

89. Ong C, Lee JH, Leow MK, Puthucheary ZA. Functional Outcomes and Physical Impairments in Pediatric Critical Care Survivors: A Scoping Review. Pediatr Crit Care Med 2016;17:e247-59. 
90. Hopkins RO, Suchyta MR, Kamdar BB, Darowski E, Jackson JC, Needham DM. Instrumental Activities of Daily Living after Critical Illness: A Systematic Review. Annals of the American Thoracic Society 2017;14:1332-43.

91. Ohtake PJ, Lee AC, Scott JC, et al. Physical Impairments Associated With PostIntensive Care Syndrome: Systematic Review Based on the World Health Organization's International Classification of Functioning, Disability and Health Framework. Phys Ther 2018;98:631-45.

92. Shankar-Hari M, Ambler M, Mahalingasivam V, Jones A, Rowan K, Rubenfeld GD. Evidence for a causal link between sepsis and long-term mortality: a systematic review of epidemiologic studies. Critical care (London, England) 2016;20:101. 93. Alam N, Nannan Panday RS, Heijnen JR, van Galen LS, Kramer MHH, Nanayakkara PWB. Long-term health related quality of life in patients with sepsis after intensive care stay: A systematic review. Acute Med 2017;16:164-9.

94. Gerth AMJ, Hatch RA, Young JD, Watkinson PJ. Changes in health-related quality of life after discharge from an intensive care unit: a systematic review. Anaesthesia 2019;74:100-8.

95. Hashem MD, Nallagangula A, Nalamalapu S, et al. Patient outcomes after critical illness: a systematic review of qualitative studies following hospital discharge. Critical Care (London, England) 2016;20:345.

96. Altman MT, Knauert MP, Pisani MA. Sleep Disturbance after Hospitalization and Critical Illness: A Systematic Review. Ann Am Thorac Soc 2017;14:1457-68.

97. Castro-Avila AC, Seron P, Fan E, Gaete M, Mickan S. Effect of Early Rehabilitation during Intensive Care Unit Stay on Functional Status: Systematic Review and Meta-Analysis. PLoS One 2015;10:e0130722.

98. Laurent H, Aubreton S, Richard R, et al. Systematic review of early exercise in intensive care: A qualitative approach. Anaesth Crit Care Pain Med 2016;35:133-49. 99. Nydahl P, Sricharoenchai T, Chandra S, et al. Safety of Patient Mobilization and Rehabilitation in the Intensive Care Unit. Systematic Review with Meta-Analysis. Ann Am Thorac Soc 2017;14:766-77.

100. Tipping CJ, Harrold M, Holland A, Romero L, Nisbet T, Hodgson CL. The effects of active mobilisation and rehabilitation in ICU on mortality and function: a systematic review. Intensive Care Med 2017;43:171-83.

101. Taito S, Taito M, Banno M, Tsujimoto H, Kataoka Y, Tsujimoto Y. Rehabilitation for patients with sepsis: A systematic review and meta-analysis. PLoS One 2018;13:e0201292.

102. Cuello-Garcia CA, Mai SHC, Simpson R, Al-Harbi S, Choong K. Early Mobilization in Critically III Children: A Systematic Review. J Pediatr 2018;203:25-33 e6. 103. Mehlhorn J, Freytag A, Schmidt K, et al. Rehabilitation Interventions for Postintensive Care Syndrome: A Systematic Review. Critical Care Medicine 2014;42:1263-71.

104. Connolly B, Salisbury L, O'Neill B, et al. Exercise rehabilitation following intensive care unit discharge for recovery from critical illness. In: Connolly B, ed. Cochrane Database of Systematic Reviews. Chichester, UK: John Wiley \& Sons, Ltd; 2015:CD008632. 
105. Fuke R, Hifumi T, Kondo $\mathrm{Y}$, et al. Early rehabilitation to prevent postintensive care syndrome in patients with critical illness: a systematic review and meta-analysis. BMJ Open 2018;8:e019998.

106. Weinreich M, Herman J, Dickason S, Mayo H. Occupational Therapy in the Intensive Care Unit: A Systematic Review. Occup Ther Health Care 2017;31:205-13. 107. Haines KJ, Beesley SJ, Hopkins RO, et al. Peer Support in Critical Care: A Systematic Review. Crit Care Med 2018;46:1522-31.

108. Schofield-Robinson OJ, Lewis SR, Smith AF, McPeake J, Alderson P. Follow-up services for improving long-term outcomes in intensive care unit (ICU) survivors. Cochrane Database Syst Rev 2018;11:CD012701.

109. Mcllroy PA, King RS, Garrouste-Orgeas M, Tabah A, Ramanan M. The Effect of ICU Diaries on Psychological Outcomes and Quality of Life of Survivors of Critical IIIness and Their Relatives: A Systematic Review and Meta-Analysis. Crit Care Med 2019;47:273-9.

110. Robinson KA, Davis WE, Dinglas VD, et al. A systematic review finds limited data on measurement properties of instruments measuring outcomes in adult intensive care unit survivors. J Clin Epidemiol 2017;82:37-46. 
Table 1: Recent Systematic Reviews Pertinent to Sepsis Survivorship

\begin{tabular}{lcc}
\hline Topic & $\begin{array}{c}\text { Number of Reviews, } \\
\text { Total (Sepsis-Specific) }\end{array}$ & $\begin{array}{c}\text { Total Number of } \\
\text { Included Studies }\end{array}$ \\
\hline Outcomes & $3^{85-87}\left(2^{85,87}\right)$ & 168 \\
Cognitive & $4^{8-10,88}(0)$ & 102 \\
Emotional & $3^{89-91}(0)$ & 53 \\
Functional & $2^{1,92}\left(2^{1,92}\right)$ & 69 \\
Mortality & $2^{93,94}\left(1^{93}\right)$ & 62 \\
Quality of Life & $2^{95,96}(0)$ & 44 \\
Other & & 88 \\
Interventions & $6^{97-102}\left(1^{101}\right)$ & 27 \\
$\quad$ Early Mobility & $3^{103-105}(0)$ & 31 \\
Rehabilitation & $4^{106-109}(0)$ & 20 \\
Other & & 592 \\
Research Methods & $1^{110}(0)$ & \\
Performance of & $\mathbf{3 0}(6)$ & \\
outcome measures & & \\
\hline Total & & \\
\hline Summaries of the 30 & & \\
\hline
\end{tabular}

Summaries of the 30 systematic reviews are presented in

Supplemental Table 1. 
Table 2: Models of success from other fields

\begin{tabular}{|c|c|c|c|}
\hline $\begin{array}{l}\text { Analogous } \\
\text { Condition }\end{array}$ & Similarities & Differences & $\begin{array}{l}\text { Successful programs, which may } \\
\text { be appied to sepsis }\end{array}$ \\
\hline Cancer & $\begin{array}{l}\text { Like sepsis, cancer and its } \\
\text { treatment commonly result } \\
\text { in new morbidity, increased } \\
\text { risk for certain medical } \\
\text { complications, and post- } \\
\text { acute mortality. }\end{array}$ & $\begin{array}{l}\text { The duration of cancer } \\
\text { treatment is longer, } \\
\text { such that patients are } \\
\text { more likely to self- } \\
\text { identify as cancer } \\
\text { survivors. A defined } \\
\text { specialty group provides } \\
\text { both the acute and } \\
\text { longer-term care. }\end{array}$ & $\begin{array}{l}\text { Large-scale registries, and an } \\
\text { International Association of Cancer } \\
\text { Registries }{ }^{59} \\
\text { Registry-RCT linkages } \\
\text { Public Awareness Campaigns } \\
\text { Philanthropy-funded research } \\
\text { Long-term follow-up clinics } \\
\text { Peer Support Groups }\end{array}$ \\
\hline Dementia & $\begin{array}{l}\text { Like sepsis, dementia } \\
\text { typically occurs in older } \\
\text { patients with multi-morbidity } \\
\text { and often requires family } \\
\text { members to take on care- } \\
\text { giving roles. Like sepsis, } \\
\text { dementia has suffered from } \\
\text { a lack of targeted therapies } \\
\text { entering the market despite } \\
\text { improved understanding of } \\
\text { its pathophysiology. }\end{array}$ & $\begin{array}{l}\text { Unlike sepsis, many } \\
\text { dementias are slowly } \\
\text { progressive diseases. A } \\
\text { defined specialty group } \\
\text { provides both the acute } \\
\text { and longer-term care. }\end{array}$ & $\begin{array}{l}\text { Regional registries of dementia } \\
\text { patients }{ }^{60} \text {. } \\
\text { Industry-academia research } \\
\text { collaboration with multi-national } \\
\text { register, standardized follow-up, and } \\
\text { intentional invitations to participate in } \\
\text { early stage 'adaptive' clinical trials } \\
\text { (e.g. European Prevention of } \\
\text { Alzheimer's Dementia Consortium, } \\
\text { EPAD }{ }^{46,47} \text { ) }\end{array}$ \\
\hline $\begin{array}{l}\text { Stroke / } \\
\text { Traumatic } \\
\text { Brain Injury } \\
\text { (TBI) }\end{array}$ & $\begin{array}{l}\text { Like sepsis, stroke and TBI } \\
\text { may be followed by } \\
\text { profound new functional } \\
\text { and cognitive limitations. }\end{array}$ & $\begin{array}{l}\text { More focal injuries with } \\
\text { discrete lesions and } \\
\text { association functional } \\
\text { and cognitive limitations. } \\
\text { A defined specialty } \\
\text { group provides both the } \\
\text { acute and longer-term } \\
\text { care. }\end{array}$ & $\begin{array}{l}\text { Structured acute rehabilitation and } \\
\text { long-term follow-up programs. } \\
\text { Regional registries of TBI } \\
\text { patients }{ }^{61,62} \text {. }\end{array}$ \\
\hline
\end{tabular}


Figure 1: Shorter and longer-term research priorities by theme

\begin{tabular}{|c|c|c|}
\hline & Shorter Term Priorities & Longer Term Priorities \\
\hline $\begin{array}{l}\text { Promoting education, } \\
\text { advocacy, and patient } \\
\text { engagement }\end{array}$ & $\begin{array}{l}\text { Build deep connections with } \\
\text { survivor groups to define and } \\
\text { achieve research priorities } \\
\text { Develop and dissemine } \\
\text { educational materials for } \\
\text { patients and families }\end{array}$ & $\begin{array}{l}\text { Build a global registry to improve patient } \\
\text { access to cohorts and trials }\end{array}$ \\
\hline $\begin{array}{l}\text { Building clinical } \\
\text { infrastructure }\end{array}$ & $\begin{array}{l}\text { Disseminate educational } \\
\text { materials for clincians } \\
\text { Incorporate post-sepsis } \\
\text { sequelae into medical school } \\
\text { curriculum and continuing } \\
\text { medical education }\end{array}$ & $\begin{array}{l}\text { Develop specialized follow-up programs } \\
\text { - dedicated clinics or sepsis centers of } \\
\text { excellence. } \\
\text { Adapt follow-up programs to incorporate } \\
\text { remote monitoring, telehealth, and in- } \\
\text { home visits. }\end{array}$ \\
\hline $\begin{array}{l}\text { Improving research } \\
\text { methodology }\end{array}$ & $\begin{array}{l}\text { - Harmonize and link existing } \\
\text { ICU databases }\end{array}$ & $\begin{array}{l}\text { Launch an integrated global cohort } \\
\text { study linking mechanism to long-term } \\
\text { outcomes } \\
\text { Complete detailed longitudinal follow-up } \\
\text { to characterize heterogeneity of recovery } \\
\text { across sepsis survivors }\end{array}$ \\
\hline
\end{tabular}


Figure 2: Conceptual diagram of patients' clinical course through sepsis and underlying factors that influence an individual patient's trajectory

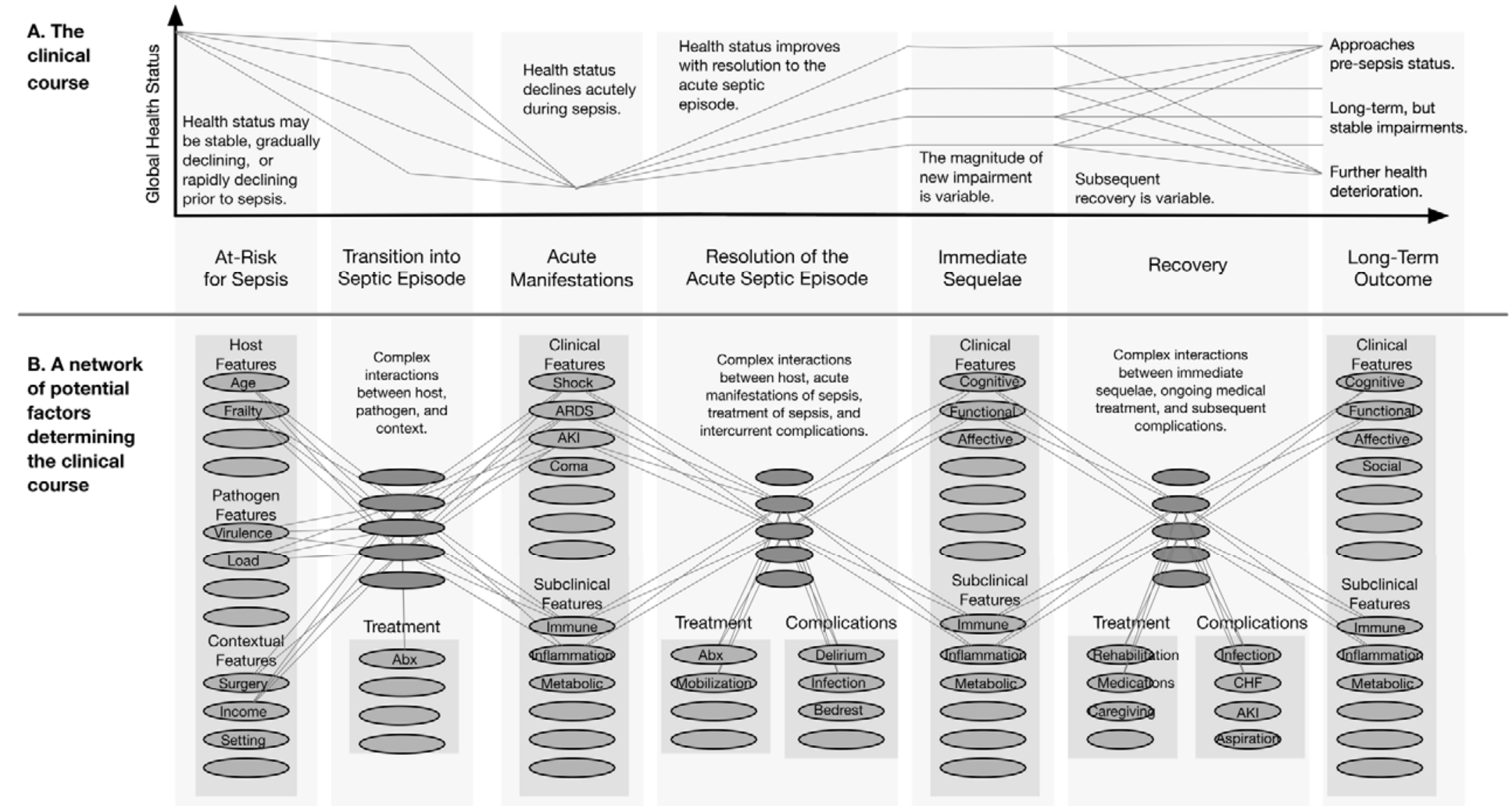

There are many potential clinical courses that a patient may experience after a hospitalization for sepsis, from rapid complete recovery to recurrent complications and death. This figure (adapted from a conceptual diagram first promoted in Prescott and Angus, JAMA, 2018²) depicts common clinical trajectories (top panel) and presents factors important to shaping a patient's clinical course and long-term outcome (bottom panel). This figure draws from the Wilson-Cleary model ${ }^{63}$, which links underlying biologic factors to 
physical function and quality of life, but extends the representation of the biologic factors to demonstrate their complex and unmeasurable interactions.

Observable factors, such as presenting features and clinical manifestations of disease, are presented as light-grey ellipses, while the unmeasurable biological interactions are presented as dark-grey ellipses. Not all ellipses are labelled, representing our incomplete knowledge of the factors determining clinical course. This diagram is intended to convey that innumerable factors interact in complex ways to determine a patient's long-term outcome, and that the measurable manifestations of disease cannot fully predict the evolution of a patient's recovery because of the unmeasurable biological interactions at play. 
Figure 3: Conceptual diagram of global sepsis registry

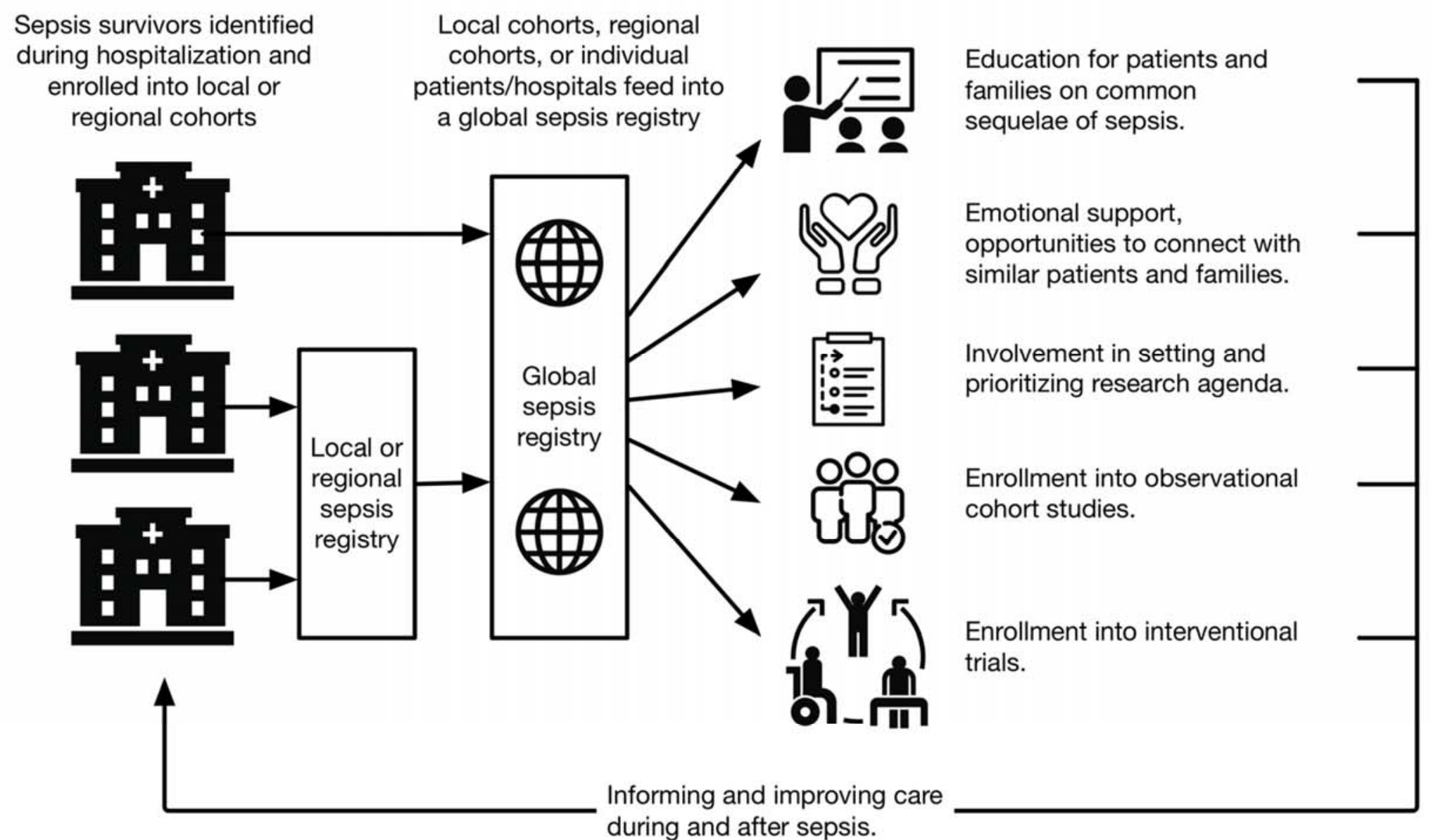

While some services (education, emotional support) are ideally provided locally or regionally, they are not universally available. A global sepsis registry could provide universal opportunities for enrollment into cohorts and interventional trials, as well as safety net services for patients without local sepsis survivorship resources. 